\title{
JARDINES EN ENTORNOS PATRIMONIALES DE LA ZONA MEDIA DE CÁCERES. DEL "LOCUS AMOENUS" AL PAISAJISMO ACTUAL
}

Ma del Mar Lozano Bartolozzi

Universidad de Extremadura

ORCID: https://orcid.org/0000-0001-5457-7890

\section{RESUMEN}

Estudio de la proyección y construcción de algunos jardines especialmente singulares en la ciudad de Cáceres, en la Fundación Xavier de Salas en el Convento de La Coria en Trujillo y en el castillo de la Arguijuela de Abajo. Jardines que fueron proyectados pero no se realizaron, otros llevados a cabo que han desaparecido y por ultimo algunos que existen en la actualidad. Los que analizamos han sido proyectados para recuperar un patrimonio que tuvieron determinados castillos, conventos y casas solariegas o espacios abiertos en centros históricos y paisajes culturales.

Palabras clave: jardines, edificios patrimoniales, provincia de Cáceres

\section{ABSTRACT}

A study of the design and construction of a number of particularly unique gardens in the city of Cáceres, at the Xavier de Salas Foundation, the convent of La Coria in Trujillo, and at the castle of Arguijuela de Abajo. Some of these gardens were designed but never built, some were built but have since disappeared, and others are still in existence today. Those under analysis have been designed to restore a heritage that was once the preserve of the castles, convents, stately homes, and open spaces in the region's historic town centres and cultural landscapes.

Keywords: gardens, heritage buildings, province of Cáceres

\section{Introducción}

El diccionario de la Real Academia de la Lengua define el jardín como: "Terreno donde se cultivan plantas con fines ornamentales", mientras que otros diccionarios añaden la frase: "para hacer de él un lugar agradable".

Son muchos los textos escritos sobre jardines en las diversas culturas y etapas de la historia. Se han hecho comentarios que atañen al estudio de la proyección y construcción de algunos jardines especialmente notables, pero han sido poco estudiados los que corresponden al ámbito territorial de este trabajo, la zona media extremeña. Su investigación puede concernir a un ámbito muy amplio y diverso, e incluso difícil de conocer pues algunos de los jardines que son mencionados por distintas fuentes no pasaron de ser proyectos que no se llevaron a cabo; otros han desaparecido y son solamente una huella arqueológica, o meramente documental fruto de descripciones históricas, literarias y con escasas imágenes gráficas.

Nosotros nos vamos a detener en algunos que se sitúan en la ciudad histórica de Cáceres, en otros relacionados con determinadas construcciones histórico-artísticas y su entorno, transformando su paisaje histórico, o con edificaciones hechas para albergar un uso cultural ${ }^{1}$.

Son jardines realizados en ámbitos religiosos y civiles. Jardines a cuyo disfrute de la vista y de los perfumados olores placenteros y sensuales de sus 

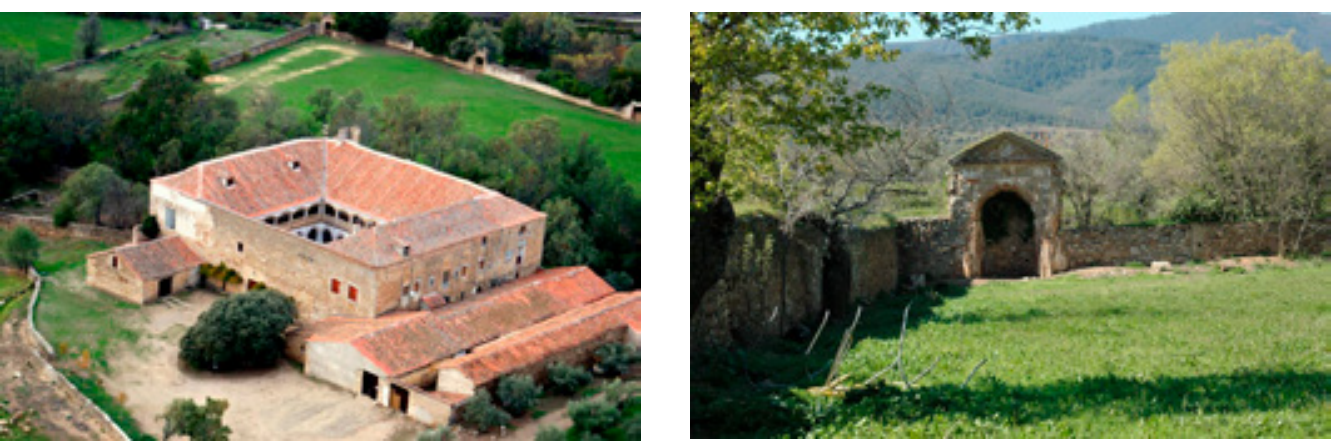

Figs. 1 a y b. Abadía (Cáceres), palacio de los duques de Alba. Vista aérea y detalle del jardín

flores, arbustos o árboles con aromas estacionales, como los cítricos, se unirán los productivos de algunos árboles frutales y especies con capacidad medicinal curativa. La mayor parte de ellos buscan constituirse en microcosmos que remontan a pequeños paraísos como ocurre con los claustros ajardinados de los conventos o los espacios de reposo intimista en propiedades privadas.

Sin duda el jardín más nombrado, valorado y documentado, es el del palacio de Sotofermoso de la Casa de Alba en Abadía, creado por el III Duque don Fernando Álvarez de Toledo en el siglo XVI, donde tuvo lugar la celebración de una Academia literaria: El Arca de Albano, pero lamentablemente conserva pocos de sus elementos originarios por el deterioro sufrido a través del paso del tiempo y de los propios trabajos agrícolas desarrollados en él. Lo que no impide que al pisar por sus plataformas escalonadas y llegar al borde del río Ambroz, para contemplar sus evocadoras portadas trazadas en el renacimiento, que hoy día aparecen con el entrelazo de la vegetación enraizada en ellas; o al ver algunas de las esculturas que se conservan en el interior del edificio y el singular patio mudéjar, no podamos, apoyados por la literatura que generaron poetas y viajeros, imaginar lo que pudo ser aquél jardín con mirtos, árboles y todo tipo de plantas olorosas, formando figuras gracias al ars topiaria, surtidores de agua y fuentes con sorpresas y juegos manieristas $^{2}$ (figs. 1 a y b).

Así mismo tenemos noticias de la existencia de otros jardines de cierto interés. Por ejemplo en Plasencia encontramos unas pasarelas o pasaderas dibujadas en el vado de San Juan, al sur de la población, en el plano que el médico Luis de Toro hizo en el siglo XVI. Dichas pasaderas fueron colocadas por el arcediano de Plasencia y Béjar que fundó una atractiva casa junto a la ribera del Jerte. Una construcción con magnífico y oloroso jardín y huerto descrito así por el mismo Luis de Toro:

en cierto amenísimo y hondo valle, está situada la elegante y ciertamente espléndida mansión del muy ilustre y recomendadisimo en linaje y virtudes Don Fabián, Arcediano de Plasencia y Béjar, está rodeada por todas partes de árboles frutales y amenos viñedos y cuidadosamente adornada con un jardín en el cual se admira el arte del jardinero... ${ }^{3}$.

Sabemos que después el citado huerto fue dejado en testamento del Arcediano a la fundación del Colegio de San Fabián y San Sebastián.

Hay jardines en edificios patrimoniales que han sido objeto de determinada recuperación histórica como el caso de la obra llevada a cabo para restaurar y recuperar la imagen de los jardines del Monasterio de Yuste en la comarca de la Vera por parte de Patrimonio Nacional, con la colaboración de Hispania Nostra. Pero también existen jardines que están siendo construídos de nuevo como complemento de la restauración de un edificio histórico, o creados "exnovo" para acompañar inmuebles con fín cultural, como museos y centros de interpretación. Estos últimos son jardines del siglo XXI que entran dentro de la valoración de conceptos en torno al arte paisajístico fomentados por la Unesco y otros organimos internacionales o nacionales como la mencionada asociación sin ánimo de lucro, Hispania Nostra. 


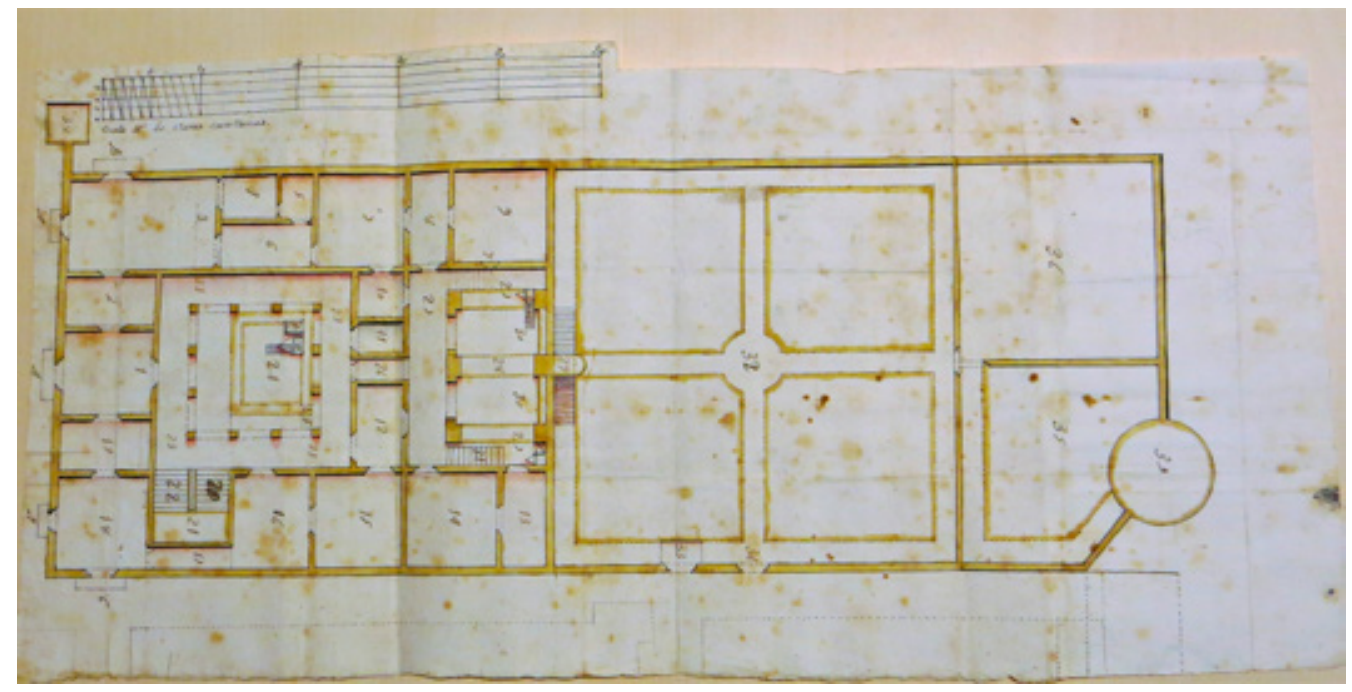

Fig. 2. Proyecto del Palacio de los Marqueses de Ovando en la Ciudad de Cáceres junto a la Puerta de Mérida. 1747. Planta general del piso principal del Palacio y los jardines. Dibujo sobre papel. Archivo del Marqués de Ovando (Cáceres). Fundación Bufalo, congregación Padres Misioneros Preciosa Sangre

Jardines que van desde la conservación de la tradición mediterránea a las apuestas más contemporáneas del uso de las plantas como decoración, pero también como introducción de un uso placentero que simultáneamente sirva de defensa medioambiental con metodologías de ahorro de energías nocivas para nuestro futuro.

En el jardín el fin primordial es la sombra como placer, la sombra como bien potencial para plantar otras especies y que prosperen gracias a ese microclima, la sombra como estética por el contraste lumínico, y siempre la reducción calórica y la economía hídrica... ${ }^{4}$.

Por tanto en este artículo dejamos atrás los parques urbanos o las plantaciones arbóreas para mejorar la ornamentación de viales, calles o plazas, como esa proliferación de alineaciones de palmeras, tan de moda, que nos encontramos en las entradas o salidas de ciudades o pueblos.

\section{Cáceres}

Algunas casas principales de la ciudad histórica cacereña, declarada Patrimonio Mundial en 1986, tanto intramuros, como fuera de los muros, disfrutaban de patios abiertos claustrados con plantas que daban sombras, buen olor y color, más algún patio y jardín con dependencias posteriores. En el Interrogatorio del Marqués de la Ensenada se da cuenta de ellos, caso del jardín de la vivienda de los Golfines de Abajo, que actualmente se está restaurando, o el del llamado palacio de Ovando o de las Cigüeñas. Como muestra comentaremos el interesante proyecto de un jardín que formaba parte de un propósito más amplio de una casa que intenta construir el primer Marqués de Ovando en el siglo XVIII ${ }^{5}$, aunque no se llegó a realizar; y el jardín de la casa de Joaquín Jorge de Cáceres y Ulloa, Aldana y Quiñones, actual Museo de Cáceres.

Sin olvidar los jardines y huertas de los conventos que gozaban de sus claustros, a los que se añadían huertos productivos, como el de Santa Clara o el del Monasterio de San Francisco. El del primero aún se conserva, no así el segundo cuyo huerto fue aprovechado como solar para edificaciones de servicios de la Diputación de Cáceres. Pero nuestro conocimiento de los jardines que hubiera en ellos es muy escaso.

En 1744, Francisco de Ovando Solís y Rol de la Cerda, segundo de la Casa de Camarena y primer Marqués de Ovando, envió, desde América, donde entonces vivía ${ }^{6}$, a su hermano Alonso Pablo de Ovando, vecino y Regidor Perpetuo de la Villa de Cáceres, y al Concejo de la misma Villa, varias cartas y dinero para compra de fin- 


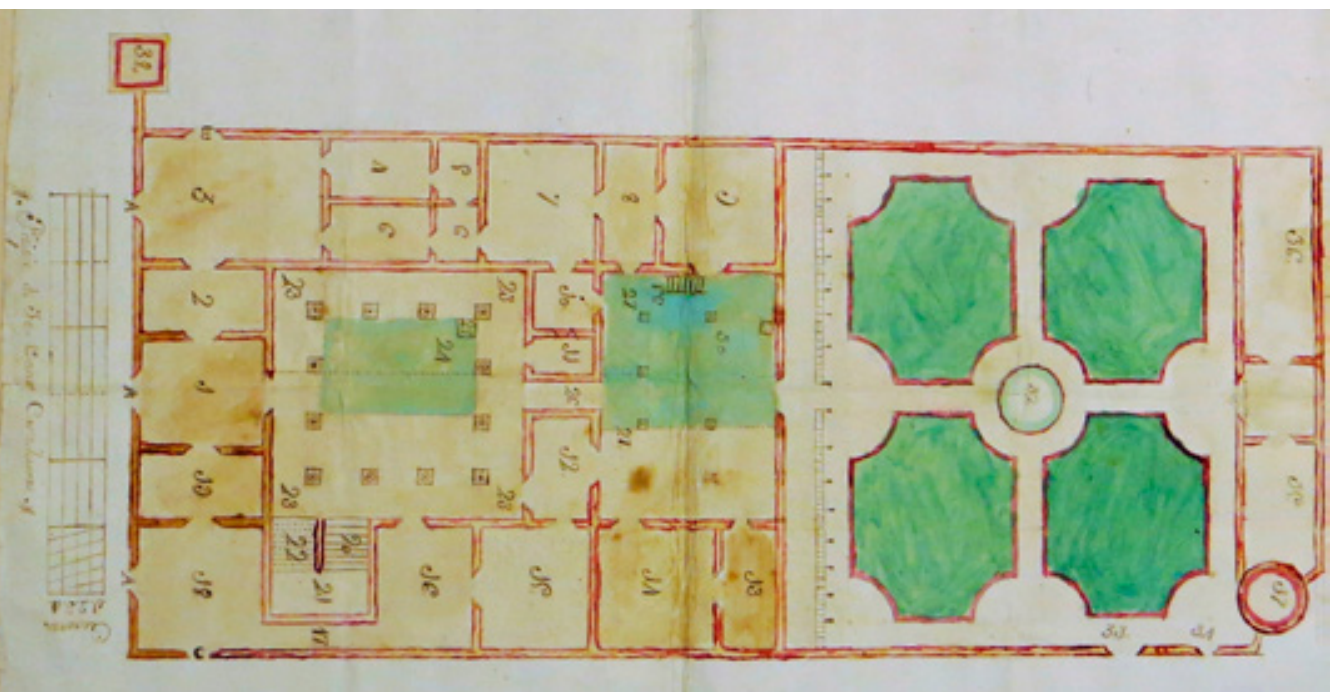

Fig. 3. Proyecto del Palacio de los Marqueses de Ovando en la Ciudad de Cáceres junto a la Puerta de Mérida. 1747. Planta general del piso principal del Palacio y los jardines. Dibujo sobre papel. Archivo del Marqués de Ovando (Cáceres). Fundación Bufalo, congregación Padres Misioneros Preciosa Sangre

cas, más el proyecto de una casa principal que pretendía construirse en la ciudad cacereña. El proyecto estaba formado por cuatro croquis detallados con indicaciones textuales adjuntas. Se trata de una vivienda de dos plantas: planta baja y planta principal, con jardín. El acceso a dicho inmueble se ubicaría en la zona de la puerta de Mérida, actual Plaza de Santa Clara, entonces denominada Potro de Santa Clara, donde estaría su fachada principal, frente a un espacio abierto en cuyo lado sur se encontraba el convento de monjas franciscanas de Santa Clara. La construcción se extendería por el cuerpo de la muralla y la barbacana exterior hacia el suroeste, incluyendo dos de sus torres, la de Santa Clara o de María Lucas y la de la Mora, denominada también torre Redonda7 (fig. 2) y en la documentación manuscrita del proyecto torre del Adarve, en el ángulo de la muralla. Las dimensiones de la casa y su jardín alcanzarían alrededor de 4000 m². Formaría un borde entre la ciudad intramuros y la calle Cornudilla extramuros. El mencionado hermano hizo en consecuencia la petición del permiso de la obra al Ayuntamiento que también le comunicó distintas resoluciones de los correspondientes acuerdos municipales. El Marqués de Ovando era un personaje importante no solamente dentro de las familias cacereñas, sino también en el mundo militar español, siendo mencionado por el histo- riador Miguel Ángel Ortí Belmonte como "cartógrafo náutico, fundador de ciudades e ingeniero naval" 8 . No es de extrañar por lo tanto su interés por intervenir en su ciudad natal con un proyecto que transformaría parte del recinto amurallado tal como observamos al publicar por primera vez este proyecto ${ }^{9}$. Recientemente el doctor Enrique Cerrillo Martín de Cáceres ha vuelto a mencionarlo en un libro sobre las murallas de Cáceres $^{10}$. Pero lo que nos interesa ahora es la importancia que da el Marqués de Ovando a la zona de jardín, tal como puede verse en los planos que adjunta (fig. 3). A pesar del envío de varias cartas (fechadas en 1744, desde Puerto Cabello en Caracas y en 1747-1748 desde México), el edificio no se llega a construir ya que el mismo espacio será solicitado por otro noble cacereño, Pablo Juan Becerra Monroy (Regidor de Brozas) ${ }^{11}$ en 1749, con la petición al mismo tiempo del derribo de la puerta de Mérida que se llevaría a cabo en 1751.

El edificio debería ser un solar que quedase independiente y aislado, derribando otras casas y restos de barbacana, que "corta la muralla", para cuya construcción solicita los materiales tanto de la muralla como de la barbacana destruidas. Como la mayor parte de los inmuebles importantes cacereños su construcción gira en torno a patios. En este caso uno principal y otro posterior. 

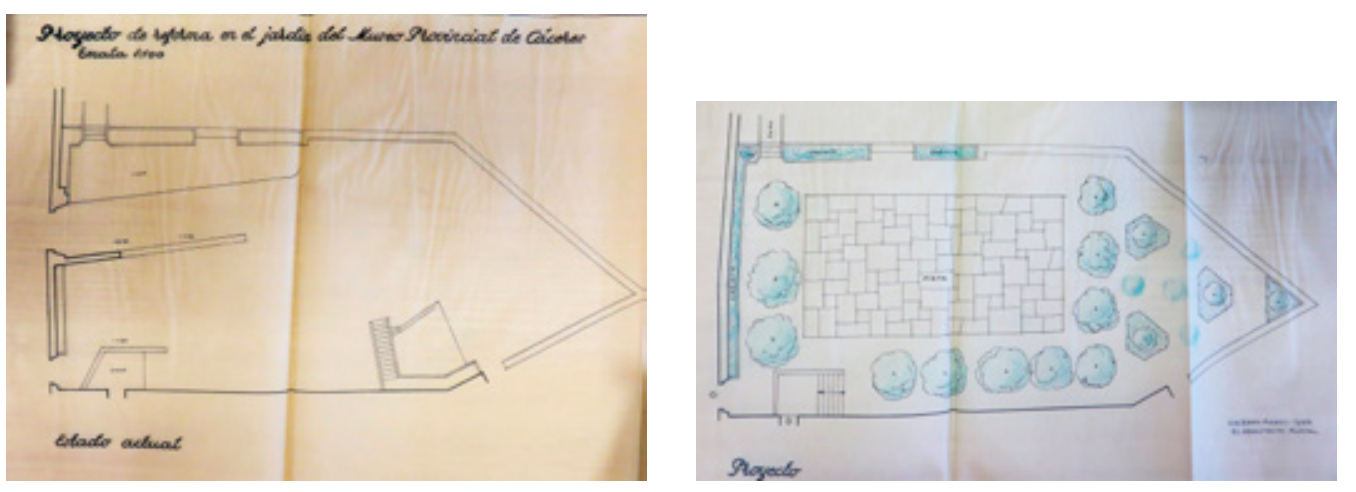

Figs. 4 a y b. Proyecto de reforma en el Jardín del museo provincial de Cáceres. Arquitecto Ángel Pérez, 1955. AMCC

Pero cabe señalar la escala del jardín. Su espacio tendría $1062 \mathrm{~m}^{2}$, por lo que el Marqués da suma relevancia este elemento relacionado con la naturaleza, lo que indica una cultura humanística del siglo XVIII que nos remonta hasta Alberti, al entender la necesaria combinación de la casa con un jardín como base de una vida placentera. Aunque los croquis son muy sencillos vemos en ellos los criterios propios de los jardines renacentistas y barrocos, basados en esquemas geométricos y perspectivas axiales abiertas hacia el horizonte, pues dicho jardín se conformaría, siguiendo el eje del edificio desde la puerta principal, con cuatro divisiones idénticas con esquinas redondeadas y una fuente en el centro. Seguramente pensaría en decorarlo con setos tallados y parterres. Los dibujos sí han plasmado los accesos tanto hacia el centro como a los laterales que marcan la forma de juegos formales simétricos.

Se trataría así de un jardín tectónico al estilo francés, lo que nos demuestra que el marqués estaba al tanto de la moda de los jardines europeos. Respecto al mismo debemos señalar algunas indicaciones escritas y numeradas que acompañan a los croquis. Por ejemplo que la habitación comedor que se encontraba en un lateral al fondo de la planta baja, abriría ventanas al jardín. Pero sobre todo interesa que una vez pasado el patio principal, que tendría un aljibe abovedado debajo, se transitaba por un corredor a un segundo patio ya inmediato al jardín. Dicha zona tendría varios elementos relacionados con el mismo, como un pasadizo sobre un arco para acceder al jardín y una puerta para bajar al mismo. En este segundo patio y corredor se construiría en la planta baja un segundo aljibe con dos bocas, para riego del jar- dín, mientras que en la planta principal se señala que este patio tendría una azotea con tres lados cubiertos y el cuarto descubierto por la parte del jardín. También se construiría una escalera desde aquí para bajar a aquél. Por último al marcar el centro del jardín se añade: «cuya vista ha de pasar por abajo desde la puerta principal y por arriba desde el balcón principal». Al final del jardín se reservan espacios para gallinas y se incluyen los torreones de la muralla. La torre redonda tendría una galería cubierta de las aguas y la de Santa Clara o de Mari Lucas estaría cubierta con 3 balcones. Por tanto se pone especial énfasis en que la vivienda tenga un corredor mirador en la planta principal sobre el jardín, al que se podría acceder desde aquélla con escaleras exteriores.

Importante jardín tuvo la casa principal de las Veletas situada en el extremo sureste intramuros, que forma borde con el barrio de San Antonio, la antigua judería vieja, en un terreno rocoso y en declive. Su origen se remonta al solar del antiguo alcázar almohade, si bien fue propiedad de la familia de Diego Gómez de Torres desde que el emperador Carlos $\mathrm{V}$ le hiciera donación de ella. Las reformas que le irán dando el aspecto actual comienzan en 1600 por Lorenzo de Ulloa y Torres. Sin embargo la vivienda no ocupó todo el espacio concedido, tal como se indica en un acuerdo del Ayuntamiento, hasta que fue solicitado el año 1751 por Joaquín Jorge de Cáceres y Ulloa, Aldana y Quiñones que hará una nueva e importante reforma, dejando entre otras la impronta de los bellos escudos barrocos de la fachada principal ${ }^{12}$ : 

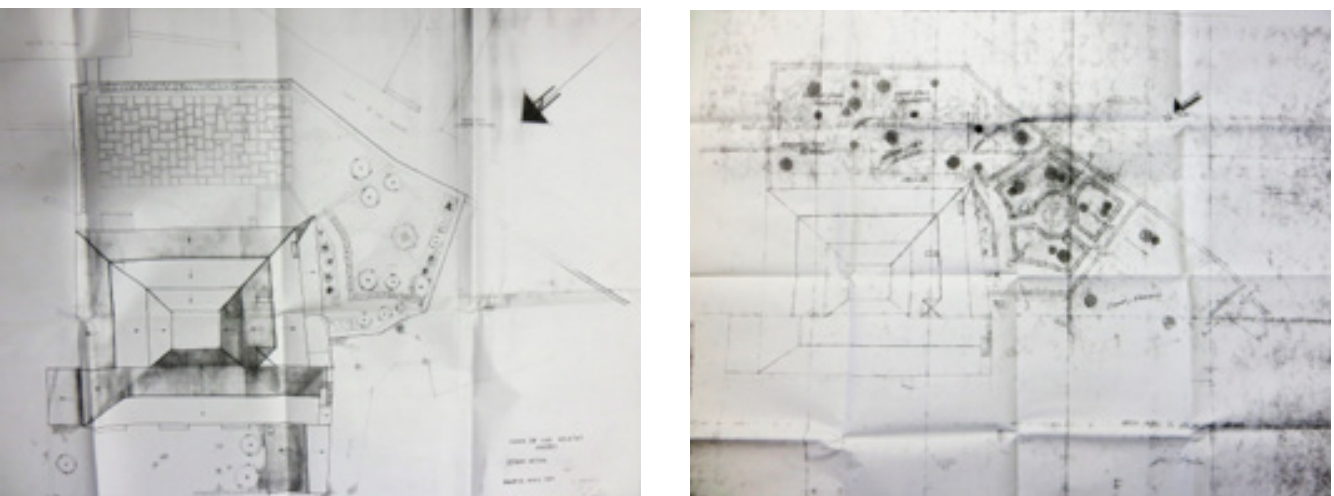

Figs. 5 a y b. Proyecto de reforma del jardín del museo provincial de Cáceres. Estado actual (1971) y reforma (1973). José Manuel Rodríguez de Valcárcel. Biblioteca del Museo de Cáceres

...hallándose oy una pendiente desde las espaldas de dicha casa a el camino que junto a ella pasa al barrio que se dize de San Antonio, necesitando el suplicante de dicha pendiente para mas largura de su casa, hermosura del sitio y hazer en el un jardín y otras ofizinas...

El edificio es actualmente el Museo de Cáceres, producto de la unión de la casa principal citada de Jorge de Quiñones (que tras ser alquilada albergaba la colección desde 1931, aunque su inauguración como museo nos lleva a 1933) y la casa de los Caballos colindante a su espalda, una antigua caballeriza, después vivienda particular y por fin espacio para exposición permanente de obras de arte. Esta última casa es propiedad de la Diputación Provincial y desde 1989 quedó anexionada al museo. Un museo cuya situación es la de dependencias del Estado, en cuanto a que este mantiene la titularidad del edificio de las Veletas y de las colecciones, más la gestión de la casa de los Caballos. Mientras que la gestión del museo, fue transferida a la Junta de Extremadura.

En el jardín del Museo se han sucedido varias remodelaciones. Así en 1955 el arquitecto municipal Ángel Pérez presenta un proyecto de Reforma $^{13}$ (figs. 4 a y b) que se justifica al escribir:

Se proyecta arreglar el jardín situado al fondo del edificio -Museo Provincial-. Hoy sin uso por la falta de rasante y abandono, para que no desentone del edificio de un servicio adecuado y pueda ser utilizado en fiestas al aire libre. Para ello se modifican las entradas en la forma más conveniente, y se quitan los añadidos posteriores al edificio, principalmente la escalera que lo inutilizaba y descompone el conjunto.

El proyecto insiste en la modificación de las desigualdades de las rasantes topográficas para dejarlo sensiblemente en horizontal con el objetivo de las posibles fiestas al aire libre. Además:

Con el fin anterior y para que armonice con el Museo, se proyecta lo más diáfano posible, y solo con unos pequeños macizos en los puntos muertos, para procurar una nota de color, que recuadre los fondos sin restar espacio para el público, y dejando libre la parte central, para una pista amplia pavimentada en condiciones adecuadas al conjunto y a su uso. Dicha pista se recuadra con los árboles que figuran en el plano los que sin restar espacio ni visualidad, darán vida al conjunto y proporcionarán una sombra conveniente.

Por último cabe añadir que:

Se proyecta también destapar una galería, en un añadido posterior al edificio, pero antiguo $y$ que armonice con el mismo, y cuyos huecos han sido tapados después, destrozando la misma, y perjudicando el conjunto.

El presupuesto incluye el derribo de una escalera que había junto a la pared y que podemos contemplar en una foto de la inauguración del museo en el año 1933. Además el derribo de varios muros para facilitar un nuevo acceso, una pista central para fiestas de losas de cantería granítica, los macizos vegetales, arriates, 18 árboles y una nueva puerta de entrada. En total sin incluir las losas de cantería son $9.640,00$ pesetas. Debemos decir que el conservador del Museo entre 
1955 y 1970 era Carlos Callejo Serrano que fue figura fundamental de su historia. Pero esta remodelación tarda un tiempo en llevarse a cabo (1959) y no se hace en su totalidad. Así mismo en el jardín se pondrán algunas piezas etnográficas, como un hórreo para su decoración.

Ya en 1971 se hace la rehabilitación del edificio proyectada por el arquitecto de la Dirección General de Bellas Artes y Arquitecto Conservador de la Ciudad Monumental José Manuel González Valcárcel, cuando el museo pasa a integrarse en el Patronato Nacional de Museos, sufriendo sus edificaciones una profunda reforma. En el plano del estado "actual" perteneciente al proyecto del citado arquitecto que reproduce lo existente en el año 1970 (figs. 5 a y b) vemos cómo el jardín responde a la remodelación propuesta en el antiguo proyecto de Ángel Pérez: con la explanada en un solo nivel y el solado pétreo de granito correspondiente. Un nuevo proyecto de González Valcárcel del año 1973, para la ordenación de la zona, supone la reforma del jardín, siendo suprimida gran parte de la antigua explanada, organizando su planta en tres nieles distintos. En el más alto junto al edificio se elimina el solado citado, se plantan arbustos ordenados en cuadrantes, y se decora con esculturas de verracos graníticos de la colección del Museo. A continuación en un segundo nivel o intermedio que linda con el muro lateral del museo que da a la calle Pereros se realiza una fuente poligonal rodeada por parterres de cuyas obras se conservan fotografías; por último se desarrolla un tercer nivel más bajo, entre el jardín y una calleja trasera cuyo espacio es transformado incorporando parte al museo ${ }^{14}$.

El año 1988 los arquitectos $M^{a}$ José Aranguren y José G. Gallegos, realizan el proyecto de reforma y acondicionamiento de la Casa de los Caballos para ser incorporada al Museo con la

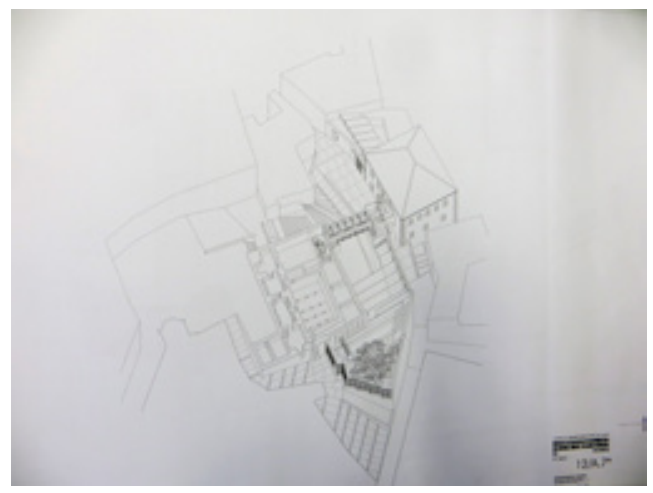

Fig. 6. Proyecto de ejecución de la rehabilitación del entorno urbano del Museo Provincial de Cáceres. Axonometría general, estado reformado. Arquitectos $\mathrm{M}^{\mathrm{a}}$ José Aranguren y José G. Gallegos. Biblioteca del Museo de Cáceres

remodelación del entorno y la construcción de un edificio como pabellón de restauración. Más tarde, entre 1998 y 2002, hacen el proyecto y obra del entorno de los jardines del Museo, que afectan al propio espacio ajardinado y a los accesos tanto de unión entre los dos edificios, como desde la calle (fig. 6). Proyectan la distribución de los espacios, a base de barandillas y muretes de hierro, pasarelas de madera, cancelas también de hierro, cuyos diseños son realizados por ellos, más superficie con césped, pavimento de granito cacereño, un estanque de agua en la zona de la calle Pereros, etc. La obra se hizo con cargo al Ministerio de Fomento, como proyecto de jardín público por lo que se realizó una puerta directa desde el callejón del Gallo, que sin embargo permanece normalmente cerrada. El lenguaje de los arquitectos es de líneas muy limpias y netas, con influencia del constructivismo artístico de las vanguardias históricas. Desde entonces el jardín ofrece la imagen que contemplamos en la actualidad (fig. 7), si bien en el año 2017 se presentó un nuevo proyecto de adecuación del Museo de
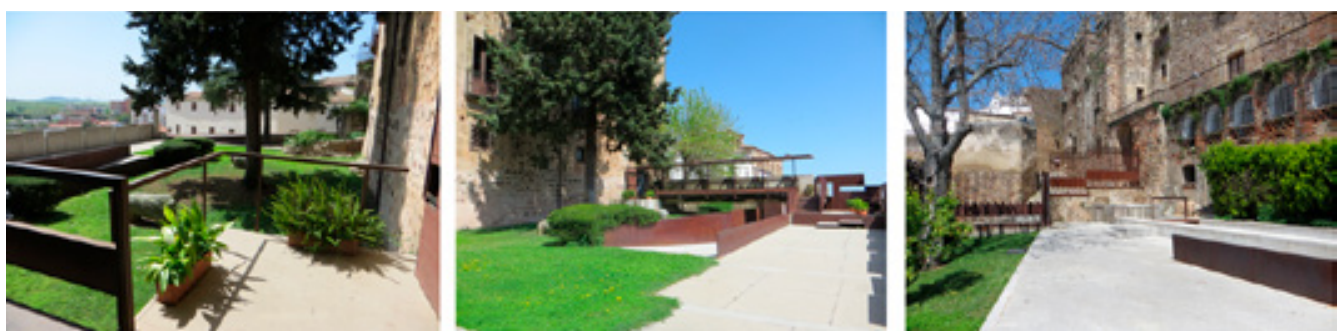

Fig. 7. Jardín del Museo de Cáceres, 26, abril 2018 


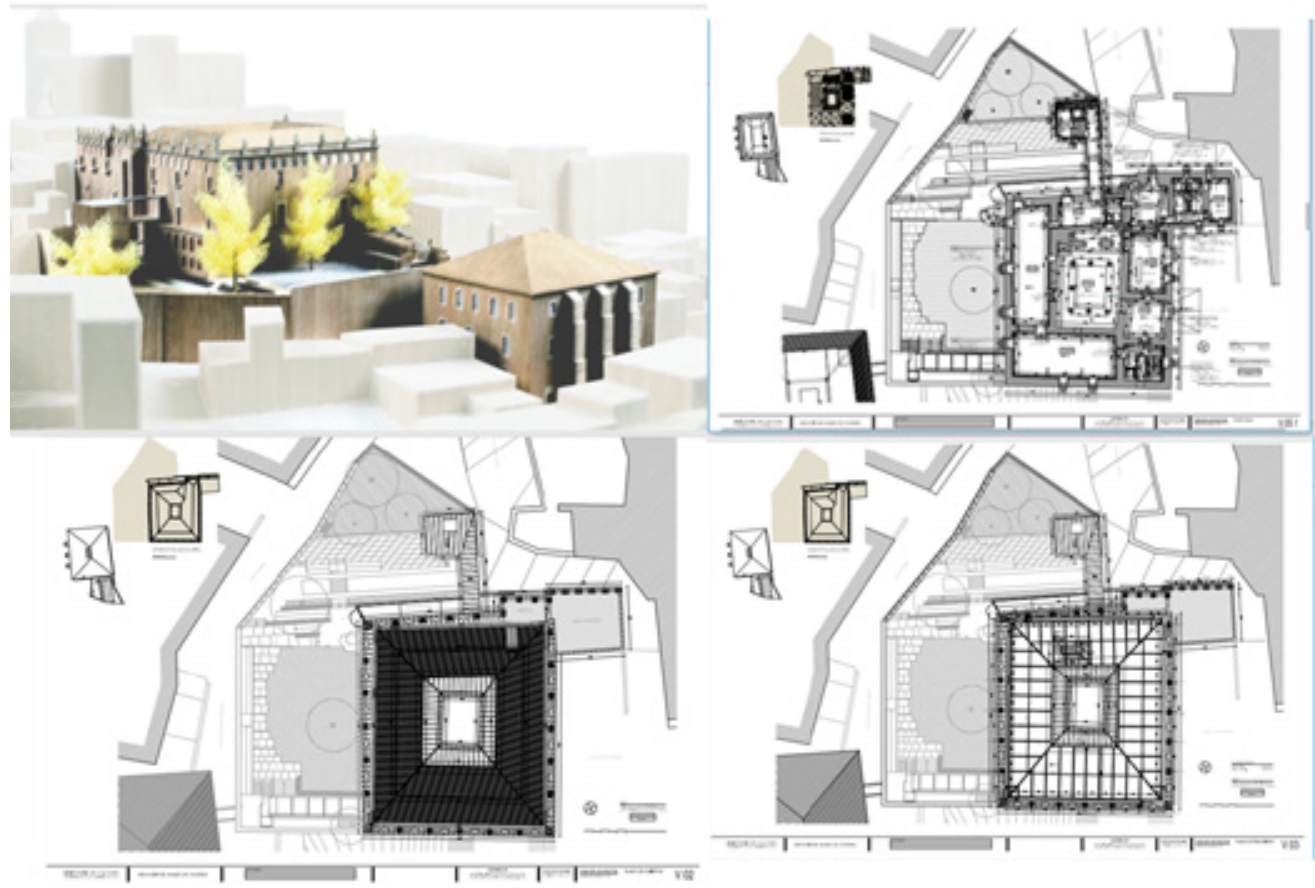

Fig. 8. Proyecto de ejecución de adecuación del museo de Cáceres, 2017. Arquitectos Valeriano Sierra Morillo, Juan Carlos Arnuncio y Jael Ortega. Fotos cortesía Museo de Cáceres

Cáceres. Un proyecto integral que afectará a sus dos edificios, realizado por la UTE formada por los arquitectos Valeriano Sierra Morillo, Juan Carlos Arnuncio y Jael Ortega y los arquitectos técnicos Juan Carlos Corona y Arcadio Conde. El proyecto básico fue realizado sin embargo por el arquitecto Andrés Celis, ya fallecido y la UTE citada ha respetado las ideas básicas.

El encargo fue del Ministerio de Educación, Cultura y Deporte y dará comienzo en el año 2019. Dicho proyecto (fig. 8) respeta la pasarela de madera de unión entre los dos edificios pero realiza algunos cambios en dicha unión o enlace con el fin de facilitar el acceso a quienes tiene problemas de movilidad. También se reforma la puerta lateral accesible desde la calle. Una especial singularidad del proyecto es que añade un cuerpo de cristaleras o pasaje transparente en la fachada lateral sur del museo para hacer accesible la contemplación del aljibe. También se mantendrá la idea de jardín de esculturas con la visualización de algunas piezas como los actuales verracos o esculturas contemporáneas. En cuanto al arbolado se intentará mantener algunos ejem- plares, como una atractiva morera, a pesar de ofrecer ciertos peligros de conservación. También se podrá visitar el llamado pasaje de la Mora debajo del jardín.

Así mismo se proyectó un jardín en la plaza que antecede al museo, donde en una fotografía fechada cerca de 1939 se pueden ver dos hileras de 7 árboles, cada una paralelas al lado de la fachada principal, que permanecerán hasta las remodelaciones de comienzo de los años setenta ${ }^{15}$. La iniciativa fue de don Álvaro Cavestany, presidente del Patronato de la Ciudad Monumental de Cáceres, que escribió al Ayuntamiento sugiriendo que se hiciera un jardín de estilo medieval en la Plaza de San Mateo. La corporación recogió la idea y el arquitecto municipal, Ángel Pérez, será quien lo diseñe y presente la memoria y el presupuesto de un jardín para la plaza de las Veletas, firmado en marzo de 1961 (fig. 9). El expediente correspondiente se encuentra en el archivo municipal ${ }^{16}$. Con tal motivo el 15 de marzo de 1961, el Alcalde envía una carta con el proyecto al Presidente de la Comisión de Monumentos Históricos y Artísticos de Cáceres, cuyo informe previo y favorable era 


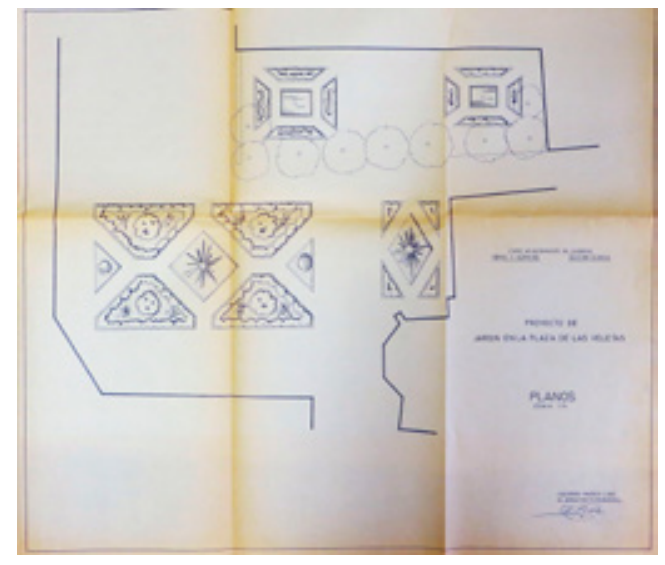

Fig. 9. Proyecto de jardín en la Plaza de las Veletas. Arquitecto Ángel Pérez. 1961. AMCC

necesario, a la que sucederán otras al instarle a dar permiso con brevedad para que no pasara la época de la plantación de especies vegetales. Se trataba de un jardín que el arquitecto justifica diciendo que daría mayor realce a los monumentos que existen en la citada plaza de las Veletas. Por ello se proyectan varios elementos distribuidos entre la fachada principal del Museo y la parte posterior del convento de San Pablo y el palacio de las Cigüeñas o casa de los Cáceres Ovando, con plantas bajas de arbustos y flores para no quitar perspectivas. Un jardín con formas geométricas poligonales. Además en el centro de dos macizos que se proyectan frente a la fachada del palacio de las Veletas se disponen dos fuentes con dos pequeños estanques. Los bordillos serían de pizarra y las piletas de solera de hormigón en masa y fábrica de ladrillo macizo de un asta con terminación de ladrillo a sardinel, guarnecida con mortero de cemento.

El presupuesto es de 58.474,98 pesetas, que sería pagado con cargo a las subvenciones para resolver el paro obrero, pues otra posibilidad que era: "Hacer gran parte de los trabajos con el per- sonal de jardines del ayuntamiento y el resto que se pagara con los propietarios de edificios limítrofes en forma de contribuciones especiales", no se considera oportuno.

Sin embargo en carta firmada el 5 de abril de 1961 por el Conde de Canilleros, presidente de la citada Comisión Provincial de Monumentos se critica tal proyecto y deniega el permiso para hacerlo tras celebrar el 4 de abril sesión de la misma y acordarse por unanimidad: «Manifestar la disconformidad de la Comisión con el citado proyecto que constituiría un anacronismo y desvirtuaría el carácter de esta zona de la ciudad antigua». Hoy vemos el espacio despejado y solamente es ocupado ocasionalmente por instalaciones efímeras como la obra de Santiago Sierra: «586 horas de trabajo», formada por bloques de hormigón que se construyó allí, durante la Feria Iberoamericana de Arte Contemporáneo (Foro Sur) el año 2001.

El espacio más representativo de la población es la Plaza Mayor, que a partir del final de la edad media y comienzos de la edad moderna se convertirá en el nodo comunicativo principal entre la propia ciudad amurallada y su puerta principal, primero Puerta Nueva y desde el siglo XVIII Arco de la Estrella, con el resto de barrios extramuros que de forma tentacular se desarrollan y comunican desde la citada Plaza. En ella hubo históricamente un pequeño jardín, pero en los años 1938 encontramos un proyecto interesante del arquitecto municipal Ángel Pérez que no se llegará a realizar ${ }^{17}$ (fig. 10). Con él se pretendía dotar a la Plaza que entonces se llamaba del General Mola, de un jardín junto al borde de la muralla delante del mencionado Arco de la Estrella, entre la torre de los Púlpitos y la torre de Bujaco, eliminando otros elementos que había allí tan singulares como la ermita de la Paz aneja a la torre de Bujaco y edificaciones del llamado
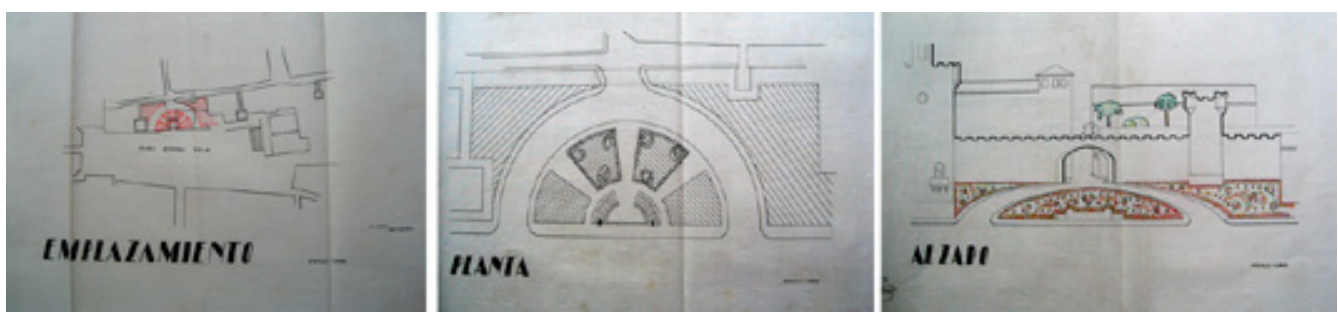

Fig. 10. Reforma de la Plaza Mayor de Cáceres. Arquitecto Ángel Pérez. 1938. AHMCC 
arco del corregidor al otro lado. El criterio era poder ver la muralla y sus torres en detrimento de construcciones posteriores a pesar de su valor histórico artístico, algo que supuso una tentación ya desde siglos pasados: suprimir elementos de la historia más reciente restaurando o reconstruyendo elementos más antiguos.

La Plaza Mayor ha pasado por distintas avatares en los que su espacio central tuvo árboles, palmeras y otras especies, que después fueron retirados, hasta que en la última remodelación de este lugar, a través del Proyecto de reordenación y urbanización de la UTE me(c)sa-THUBAN de los arquitectos Asunción Rodríguez Montejano, Antonino Antequera Regalado y Francisco Pol Méndez, finalizado el año 2011, se planteó un pequeño jardín de verano, en la zona sur, con unos árboles que han ido creciendo poco a poco.

Otros pequeños jardines se han realizado a lo largo del siglo XX y XXI en la ciudad de Cáceres. Un ejemplo es la casa principal perteneciente a los herederos de Dolores de Carvajal y su marido, Alvaro de Cavestany, hoy denominado Palacio de Carvajal, que fue adquirida por la Diputación Provincial en 1985, y al año siguiente se situó allí el Patronato de Turismo, Artesanía y Cultura Tradicional. En ella sobresale un jardín interior después de atravesar el patio porticado, donde se encuentra una higuera de gran antigüedad. Este espacio es utilizado para encuentros culturales y sociales. También para exposiciones efímeras. Es el caso de la celebración de la citada Feria Iberoamericana de Arte Contemporáneo (Foro Sur) el año 2001, en el que se expuso un banco realizado por el artista Pello Irazu (calificado de escultura-mueble de uso doméstico). Formaba parte de la muestra Dentro y fuera, comisariada por Aurora García, y desarrollada sobre diversos enclaves con obras de Susana Solano, Monserrat Soto, Daniel Canogar, Rui Chafes, Rui Sanches además de esta citada de Pello Irazu'18.

Se añaden algunos más también intramuros como el llamado Jardín de Ulloa, o el jardín de la Judería al exterior de la torre de los Pozos. Así mismo la ciudad está bordeada en su lado sureste por la rivera del arroyo del Marco. Junto a su cauce se desarrollaron a lo largo de la historia, huertas, molinos y alguna propiedad con casa de recreo y la consiguiente zona verde, como el de la familia Martín Pedrilla, hoy Museo Pedrilla que en los años noventa fundó la Diputación de Cáceres. Su jardín fue restaurado y se le añadieron algunas esculturas de Torre Isunza y una del ecuatoriano Guayasamín.

También las viviendas construidas a lo largo de la calle Pizarro, extramuros, principalmente en las primeras décadas del siglo XX, aprovecharon el fuerte desnivel existente, para construir jardines. Entre ellas, la denominada "casa Grande", donde actualmente se encuentra la Fundación Centro de Artes Visuales Helga de Alvear. Otras colindantes los conservan para uso particular o de negocios de hostelería.

\section{La Fundación Xavier de Salas en el Con- vento de La Coria de Trujillo y su Jardín in- terior}

Como ya hemos escrito la actividad de conservación y rehabilitación de edificios históricos ha ido acompañada en ocasiones de la dotación de espacios ajardinados. Así ocurre con La Fundación Xavier de Salas en el Convento de La Coria de Trujillo, creada en 1981 por el catedrático y director del Museo del Prado Xavier de Salas y su mujer Carmen Ortueta ${ }^{19}$. La sede es un antiguo convento de monjas del siglo XV (San Francisco el Real) que se encontraba en ruinas. En el interior se localiza un claustro abierto que utilizarían las monjas como espacio tranquilo, apacible y sagrado, en el que la paisajista Consuelo Martínez Correcher $^{20}$ realizó lo que ella misma llama un jardín interior ${ }^{21}$. Consuelo lo ha comentado en distintas ocasiones, como en la entrevista que le hicieron para el programa cultural de Televisión Extremadura, El lince con botas. En él afirma que no redactó un proyecto sino que solamente fue un acuerdo verbal con doña Carmen Ortueta. Así planteó un espacio geométrico con un "tipo de plantación continua de una misma especie, boj (lonicera nítida), y en superficies planas, lo que se llama en jardinería mesas" que cubren con forma de ángulos y el espacio entre las cuales corren unos canalillos de agua cuyo líquido cae en un pozo central. Ella misma califica de austera y nítida la imagen resultante que se conserva tal cual respetando el trazado original.

También tuvo el gran acierto de intervenir en las ruinas de la iglesia, que tras la restauración 
quedaron como un espacio lleno de belleza romántica conservando sus vestigios consolidados y no reconstruidos. La intervención vegetal fue realizada en esta ocasión "Con plantas trepadoras muy pegadas a la pared para que parecieran trepadoras o tapices antiguos..." (fig. 11).

Pero además en septiembre de 1999 se proyectó un jardín exterior en el lado sudoeste del edificio, no realizado finalmente, cuyo proyecto se conserva en el archivo de la propia fundación bajo la denominación: "Recreación de la huerta del museo convento de La Coria Trujillo, Cáceres". Proyecto presentado por la empresa Moraime Jardinería y Paisaje, redactado por el paisajista Jesús Martín y Hernández-Cañizares por encargo de la Fundación Caja Madrid y Fundación Hispania Nostra. El proyecto incluye una memoria que cuenta con un estudio histórico sobre el convento de La Coria, realizado por Isabel Ordieres con tal fin. Se añaden los antecedentes históricos de los jardines y en especial los de espacios religiosos, con profusos datos documentales y bibliográficos, más las mediciones y otras informaciones propias de un proyecto constructivo. Se acompaña de 12 planos, así como la indicación de algunas reformas sobre el proyecto inicial por ajuste económico. El presupuesto total de la obras es de 5.999, 975 ptas. El objetivo expresado es recrear un jardín tipo jardín hortícola o huertas ajardinadas, a tenor de los realizados en los siglos XV y $\mathrm{XVI}$, con influencias mudéjares, sin olvidar las condiciones climatológicas y el medio físico del propio lugar. Pero también se hace la salvedad que la antigua huerta de las monjas, al oeste del claustro, ocuparía el espacio del actual cementerio, mientras que el espacio señalado para el actual jardín, al suoreste, fue adquirido por la Fundación Salas y estuvo ocupado anteriormente por huertos y corrales asociados a casas de origen medieval después derribadas y convertidas en solar ${ }^{22}$.

En los planos del jardín se distinguen cuatro ámbitos: terraza alta o jardín de simples, terraza media o de las aromáticas, terraza oriental y huerta baja (fig. 12). En ellos se aportan las líneas y mediciones generales, la plantación en distintas terrazas o bancadas que permiten además determinadas vistas, a diferentes niveles, de las propias especies en las que también se busca
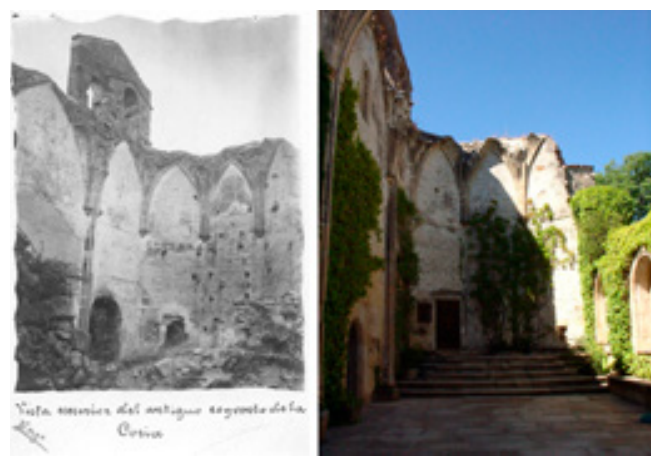

Fig. 11. Fundación Xavier de Salas en el Convento de La Coria de Trujillo

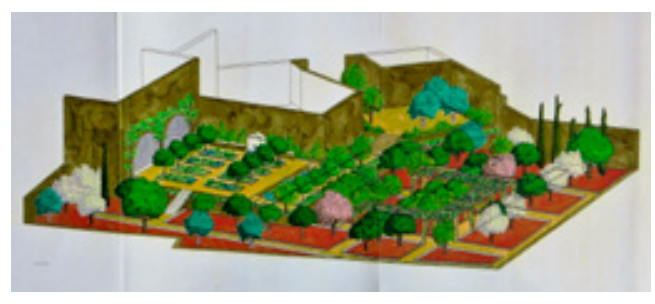

Fig. 12. Recreación de la huerta del museo convento de La Coria Trujillo, Cáceres. 1999. Proyecto empresa Moraime Jardinería y Paisaje, redactado por el paisajista Jesús Martín y Hernández-Cañizares. Biblioteca Fundación Xavier de Salas en el Convento de La Coria de Trujillo

una policromía atractiva. El espacio inferior es la denominada huerta baja, reservada para frutales.

Las especies arbóreas tienen distinto carácter: ornamental, como el árbol del cielo y el cinamomo; de aprovechamiento, caso de varios cítricos (naranjo, pomelo y limonero) y otros frutales como melocotonero, albaricoquero, membrillero, ciruelo, peral, moral, olivo, nogal, almendro, granado, higuera, palmera datilera; o de carácter simbólico, como el ciprés común, que además de plantarlo en solitario también formaría setos. Se incluyen de igual modo arbustos, como adelfas, madroño, boj, jara, escoba blanca y amarilla, jazmín, laurel, arrayán, aligustre; trepadoras como jazmín común, rosa silvestre, madreselva, mosqueta amarilla y blanca. Más vid/parra, para dar sombra, sandía, melón y lirio azul; y especies medicinales y flora de procedencia americana. Siempre pensando en constituir un vergel. Se detallan los sistemas de riego, muros y rampas, las escaleras, y la construcción de una fuente; curiosamente cuando se especifican los materiales para la misma se indica, «machón de la fuente, 

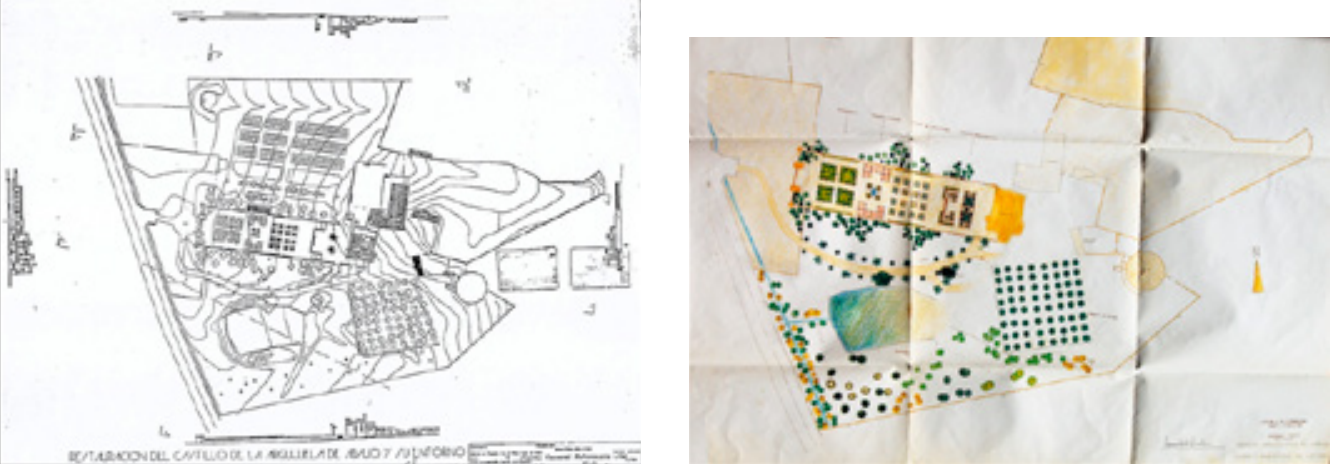

Fig. 13. Proyecto del jardín del castillo de La Arguijuela de Abajo. Plano de Fernando Hernandez-Gil Mancha y Manuel Viola arquitectos. Dibujo del proyecto, Consuelo Martínez Correcher, arquitecta paisajista. 1995. Biblioteca de don Ramón Jordán de Urríes, Vizconde de Rodas

$\mathrm{m}^{3}$ de granito, reutilizados de los encontrados en la excavación arqueológica y trasladados al jardín o comprados o puestos en obra». La expectativa de encontrar materiales graníticos en las excavaciones con motivo de la obra vuelve a tenerse en cuenta en la bancada y otros elementos a construir.

En cuanto a las labores de plantación y trasplante, se aprovecharían los árboles que ya existen. Además el proyecto aporta tres visiones en color que reproducimos: 1.-Vista axonométrica I. Líneas generales. Obra civil y definición de superficies. 2.-Planta general. Líneas generales. Obra civil y plantación. 3.-Vista axonométrica II. Líneas generales. Obra civil y plantación.

\section{Un jardín de evocación en un castillo del territorio cacereño}

En el entorno de la capital cacereña se construyeron varios castillos o casas fuertes, y casas de campo ${ }^{23}$. Entre ellos los dos castillos de las Arguijuelas que lindan con la carretera nacional 630, por donde transcurrió la Vía de la Plata. El de las Arguijuela de Abajo se asienta en un terreno muy llano y nos remonta en origen al siglo XV y a don Francisco de Ovando "El viejo", cuando se construye un castillo o casa fuerte y dependencias agropecuarias para la explotación de la finca. Si bien la primitiva casa fuerte tuvo reformas posteriores, sobre todo en el siglo XVI con Francisco de Ovando Mayoralgo, así como en el siglo XVII y en el siglo XIX. Hoy es Bien de Interés Cultural. Antonio Navareño que la ha estudiado y descrito, comenta que ya en el siglo XV tuvo una cerca o muralla de poca altura y cubos en las esquinas, con almenas sobre canecillos. Su dotación de elementos defensivos debió tener como finalidad expresar más el poder de sus propietarios y la prestancia, que poder afrontar posibles ataques enemigos. También se encuentra una ermita al otro lado de la carretera mencionada. Se sabe además que a principios del siglo XX tenía, entre otros elementos, terrenos adehesados, tres olivares, un pozo, dos charcas, más un jardín y una alameda. Ya a los últimos años del siglo XX, el propietario, don Ramón Jordán de Urríes, Vizconde de Rodas, decidió acometer su restauración para uso de esparcimiento y representación social. Hoy, por su impactante atractivo patrimonial y pintoresquista, es uno de los espacios más concurridos para la celebración de bodas y otros eventos sociales. Al tratamiento del propio castillo y entorno inmediato se une el resto de construcciones; cobertizo para los animales, una pequeña plaza de tientas y sobre todo el placentero piasaje de dehesa por que la explotación agropecuaria continúa existiendo.

El proyecto de conservación y rehabilitación fue obra de los arquitectos Fernando Hernández-Gil Mancha y Manuel Viola Nevado (1995). Además se incluyó la creación de un jardín, ante la fachada principal del castillo situada al poniente, donde se encontraba un amplio espacio rectangular o cerca construida en el siglo XIX, con criterios neogóticos propios de la época. Sus dimensiones son de 120 metros de longitud por 30 metros de anchura, cerrado por un muro de 


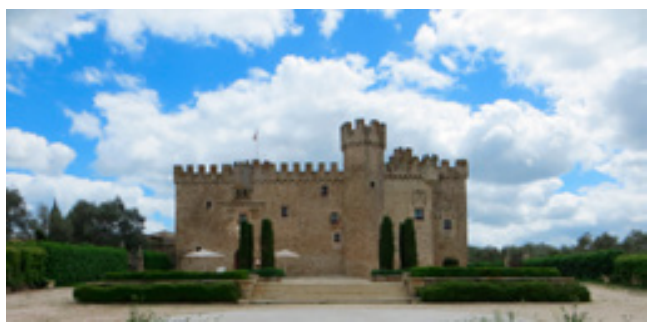

Fig. 14. Detalles del jardín de la Arguijuela de Abajo, 28, abril, 2018

mampostería, con algunas almenas y puerta de arco de medio punto de cantería con cancela de hierro. El telón de fondo, al entrar en el recinto por el citado jardín, lo constituye la fachada del castillo que fue embellecida en distintas fases del siglo XVI con blasones de Ovando Mogollón y el característico elemento del alfiz sobre ellos, un matacán semicilíndrico, nuevas almenas, la atractiva torre también blasonada, en un juego alejado de toda simetría.

Nuevamente nos encontramos como autora de dicho jardín a Consuelo Martínez-Correcher que realizó una memoria ${ }^{24}$ con un formato que se aproxima a un libro de artista, al que acompaña un plano y el proyecto que forma parte de todo el expediente de restauración del conjunto (fig. 13).

El libro memoria, de cuidado diseño firmado en 1995, tiene varias páginas manuscritas, además de fotografías del castillo antes de la construcción del jardín, a lo que añade dibujos de trazados de setos geométricos y otros elementos, más la exposición de algunos antecedentes para la realización de un jardín exnovo, como testimonios literarios y representaciones plásticas de los siglos XV y XVI, además de sus conocimientos eruditos de los jardines a lo largo de la historia. Creemos de interés reproducir algunos de los párrafos de dicha memoria que aportan un contenido conceptual, simbólico, y una metodología de trabajo en un campo tan interesante como es el paisajismo y la jardinería.

Hay que insistir, como lo ha hecho la autora, que al no existir ninguna fuente gráfica o vestigio real del posible jardín en el castillo, nunca se planteó el proyecto como una recuperación de jardín histórico sino como una recreación evocadora que utilizase como fuente los jardines del siglo $\mathrm{XV}$ : tanto de la baja Edad Media como del Rena-
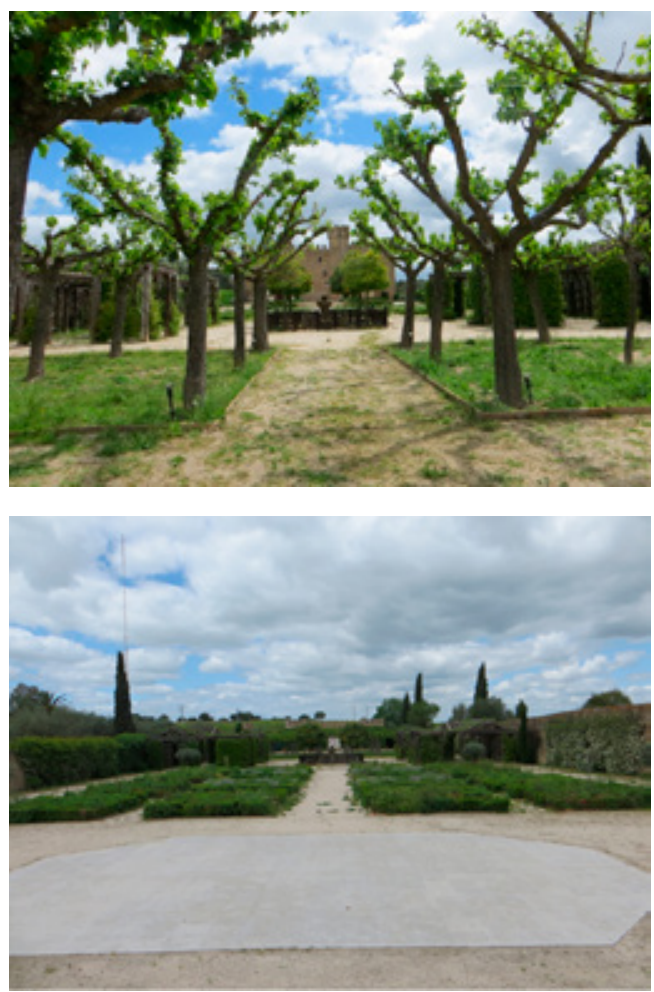

Fig. 15. Detalles del jardín de la Arguijuela de Abajo, 28, abril, 2018

cimiento, acordes con la época de la edificación. El espacio elegido tenía dos palmeras datileras muy erguidas (que se podían ver en una pintura conservada por la familia) y un almendro, que se conservaron en todo caso, si bien las palmeras que estaban muy envejecidas acabaron perdiéndose y tuvieron que ser eliminadas (fig. 14).

La autora decidió dividir en cuatro tramos todo el espacio para compartimentarlo y lograr distintos ambientes en un lugar tan largo y estrecho, tras hacer una nivelación del terreno con suave caída hacia la entrada del jardín, que tiene una verja de hierro. Al entrar por esta puerta principal vemos el eje de todo el jardín que desemboca en la fachada del castillo. Por aquí se da acceso al tramo más bajo, que denomina: Pomarium, «recuerdo del huerto de frutales de lejana tradición romana y medieval de situación campestre». Como ocurre en el resto del jardín domina el trazado en crucero y cuatro áreas de plantación que serán también una constante. La especie que las 
configuran son una plantación de moreras que con sus frondosas copas y las ramas podadas que se juntan al crecer forman un tejido a modo de toldo que proporciona una sombra espesa y una pantalla de intimidad visual ${ }^{25}$.

El siguiente tramo se llama de la Fuente Sellada (fig. 15). Lo forman un eje longitudinal con una fuente en el centro y dos estructuras laterales de madera. La intención de esta zona, que la autora considera lo más significativo del jardín, fue crear una fuente sellada como advocación mariana con el agua como recurso ineludible en un jardín. La fuente de forma octogonal está construida con piezas pétreas, reaprovechadas, que estaban diseminadas por la propia finca: fustes de columnas, un capitel, un vaso circular y una piedra de moler, y se encuentra dentro de un recinto vallado de madera de celosías con un naranjo en cada esquina: "En recuerdo de las fuentes de los "Hortus Conclusus" símbolo de vida y de purificación, bienes preciados que se resguardaban simbólicamente». En los laterales, las citadas estructuras de madera constituyen un recuerdo monacal, a modo de unos eremitorios existentes en jardines para el recogimiento y el retiro. Su finalidad, dadas sus dimensiones, es también proporcionar sombra como lugares de estancia. Las estructuras de madera están cubiertas lateralmente por trachelospermum jasminoides, es decir por jazmín que aporta un agradable perfume aromático y cubiertas con parras propias de los jardines desde la antigüedad.

A continuación se plantó un jardín de aromáticas que seguía una tipología de cronología contemporánea a la construcción del castillo:

Un jardín de crucero compuesto por un camino transversal que forma cuatro áreas o cuadrados que a su vez pueden subdividirse en cuatro, lo que constituye la fórmula magistral de la historia de los jardines... Los cuatro cuadros principales vueltos a dividirse en cruz dan dieciséis cuadrados que se plantan con setos de aromáticas formando lazos. Son dos los modelos que resaltan los diferentes cuadros. Uno en los cuatro cuadros centrales, lo que produce un núcleo central con dibujos de lazos o nudos de tradición europea. El segundo modelo que se repite en los doce cuadros restantes alrededor del primer modelo, tiene una definida inspiración mudéjar, por tanto hispánica, también se compone de setos de aromáticas haciendo lazos o nudos. Este diseño tiene una explicación analógica con la distribución del "Patio de los Evangelistas" de El Escorial en época de Felipe II, por medio de los números: cuatro elegidos entre doce, los Evangelistas entre los apóstoles.

Los citados nudos se formaron con setos de buxus sempervirens En el centro de estos cruceros se situaron parte de columnas, reaprovechas como restos arqueológicos de la finca, de ladrillos redondos cubiertos por estuco. La autora explica así mismo que la fuente de inspiración para este jardín de aromas fue el jardín nerorrenacentista que hiciera un extremeño de Don Benito: Joaquín Carvallo, al adquirir en 1906 el castillo de Villandry en La Touraine (Francia). Y añade que la finalidad de este jardín de crucero de nítidos perfiles y poca altura, es extenderse por tierra como una verdadera alfombra de finos entrelazos. En los muros laterales se plantan varias especies de arbustos y trepadoras que los cubren en su mayor parte, diferenciando sin embargo las zonas. La correspondiente a este jardín de aromas con algunas propias de los jardines del siglo XIX, época de los muros.

Por último, tras un espacio vacío para facilitar cualquier ocupación de público, se extiende la terraza superior separada por un murete de piedra y un tramo de escaleras centrales, que se pensó como plataforma para posibles escenarios de eventos como conciertos o danzas con el mencionado telón de fondo de la fachada del castillo. En la actualidad este espacio es utilizado para comedor al aire libre de eventos de bodas y otras fiestas. En la plataforma planteó organizar un jardín emblemático sobre un sector cuadrangular. Respecto a las palmeras consideradas testimonio del pasado, decidió envolverlas con "una elevación del terreno en forma de jardinera típicamente renacentista, la llamada "multiforme" ...donde cabían cuatro cipreses y una trepadora de flores de la pasión. Alrededor se pondrían cuadros de boj recortado representando signos heráldicos, las conchas y la cruz de Calatrava de la familia de los Ovando que se encuentran en los escudos de la fachada. Sobre los muros laterales se haría una plantación de frutales de espaldera haciendo dibujos". La terraza es a su vez el punto de mira principal hacia todo el jardín que se extiende 
delante de ella con un eje de perspectiva central que llega a la puerta de entrada, solamente interrumpido por la fuente sellada, pero a su vez con tramos de diferente diseño que sirven para compartimentar con relatos de distinto significado y tratamiento.

Consuelo insiste en la importancia que tuvo para ella el cálculo de las proporciones de cada espacio y la organización de la luz capaz de producir tanto las sombras necesarias para la climatología cacereña, como para producir juegos lumínicos con modulaciones de especial belleza.

A lo largo de los muros laterales del jardín, en su lado exterior, se trasplantaron viejos olivos alineados con cipreses de forma irregular. A decir de la autora: "Este tratamiento paisajístico se ha llevado a cabo en ambos costados exteriores del muro con lo que la figura del rectángulo estrecho y largo ha quedado ensanchado e integrado en el medio". También fuera del recinto y en la zona sur del castillo se encuentra un estanque con un entorno que fue remodelado "con una plantación arbórea que sigue las líneas de recogida del agua de escorrentía, como si fuera un regato, y del canal que corre paralelo a la carretera. La plantación sigue un orden paisajístico de agrupaciones fuera de todo ritmo matemático. Las especies en su mayor parte son las apropiadas a los cursos de agua, un riachuelo en el campo".

Por último cabe señalar el tratamiento de un antiguo olivar con líneas de a 8:

Alineado en líneas rectas de plantación, verdadero huerto de olivos, ha sido rodeado de murete de piedra para subrayar su forma geométrica y cerrar su espacio. Ha sido preservada su existencia como parte característica del paisaje humanizado de Extremadura, gracias a la proximidad del ramaje de sus copas se forma un verdadero entoldado perfectamente apropiado para acoger a los asistentes de alguna actividad bajo su sombra, y siendo también un espacio de estancia el huerto de olivos, aunque definido por sus líneas, se diferencia esencialmente del jardín murado, de refinado interior y espacio de estancia privilegiado.

Este olivar y su entorno son utilizados para los diversos eventos de la empresa. También menciona la proyectista su preocupación por las vistas exteriores del castillo desde la carretera y el paisaje que lo circunda con la plantación de alineaciones de cipreses, palmeras, más la conservación de un gran eucalipto al borde del estanque, además de una gran morera.

La reciente visita que hemos efectuado a este singular jardín nos demuestra que a pesar de su buena conservación y uso, no es fácil hacer toda la lectura visual y conceptual que propone la autora, por lo que quizás se podría plantear una cartelería adecuada, así como cuidar más la poda con el ars topiaria necesario de los setos que tienen formas determinadas tanto en la zona de la terraza como en la del jardín de aromas.

\section{Conclusión}

El patrimonio cultural y paisajístico de los jardines pertenece a un mundo muy frágil que hay que valorar y cuidar. Sin duda su carácter de temporalidad ha hecho que hayan desaparecido en muchos casos o al menos se hayan transformado, pero la sensibilidad que nos transmiten sus trazados, su estética, la simbología o la poética unida a distintas culturas, nos obliga a catalogarlos y documentarlos como cualquier otra obra de arte y sobre todo a que sean respetados para conservar con fidelidad las indicaciones de quienes los han creado con inteligencia, experiencia y criterios artísticos. 


\section{NOTAS}

1 Este trabajo se incluye en el proyecto de investigación nacional: «La Patrimonialización de un territorio: conformación de paisajes culturales entre el Tajo y el Guadiana en Extremadura» HAR2013-14961-P, financiado por el Ministerio de Economía y Competitividad.

$2 M^{a}$ M. Lozano Bartolozzi, "El Arca del Albano: Jardín de Abadía", revista Periferia, Colegio de Arquitectos de Andalucía Occidental, vol. II, pp. 7890, 1984. P. Navascues, La Abadía de Cáceres: espejo literario de un jardín, Anuario del Departamento de Historia y Teoría del Arte, n. 5, 1993, pp. 7190. J. Maldonado Escribano, "La Cuenca del río Tajo y sus casas de campo en la Alta Extremadura", en Patrimonio cultural vinculado con el agua: paisaje, urbanismo, arte, ingeniería y turismo ( $\mathrm{M}^{\mathrm{a}} \mathrm{M}$. Lozano Bartolozzi y V. Méndez Hernán (coord.), Editora Regional de Extremadura, Mérida, 2014, pp. 171-188.

${ }^{3}$ M. Sayáns Castaños (Presentación y comentarios), Descripcion de la Ciudad y Obispado de Plasencia por Luis de Toro. Físico y Médico de Plasencia del siglo XVI, La Victoria., Plasencia, 1961, pp.51-52.

${ }^{4}$ C. Martínez-Correcher y Gil, "Jardín Mediterráneo. El jardín tradicional mediterráneo y su papel en el ahorro del agua", Avances en Xerojardinería, Compendio de Horticultura, 12, (Coord. S. Burés) Ediciones de Horticultura, Junta de Andalucía, Reus, p.134.

${ }^{5}$ Archivo de los Marqueses de Ovando (Cáceres), L 7 A, n 30, Sec. Ovando. Fundación Bufalo, congregación Padres Misioneros Preciosa Sangre.

${ }^{6}$ El Rey nombró a este noble cacereño Inspector y Comandante General del Mar del Sur, Jefe de las Reales Armadas de la Escuadra, Mariscal de Campo, Capitán General de las Islas Filipinas y Presidente de la Real Audiencia de Manila.
7 E. Cerrillo Martín de Cáceres, La des-construcción de la muralla de Cáceres, Excmo. Ayuntamiento de Cáceres, Cáceres, 2017, p. 271

8 M.A. Ortí Belmonte, Los Ovando y Solís de Cáceres, Badajoz, 1932, p. 75.

${ }_{9} \mathrm{M}^{\mathrm{a}}$ M. Lozano Bartolozzi, "Una utopía constructiva: Proyecto de un palacio en el Cáceres del siglo XVIII que no se llegó a realizar", Academia. Boletín de la Real Academia de Bellas Artes de San Fernando, $n^{\circ}$ 50, 1980, pp.159186.

${ }^{10}$ E. Cerrillo Martín de Cáceres, La des-construcción de la muralla de Cáceres, opus cit, pp. 115.

${ }^{11}$ Ibídem, p. 115.

${ }^{12}$ E. Cerrillo Martín de Cáceres, La des-construcción de la muralla de Cáceres, opus cit, p.42. AHMCC., 18/138.17 de marzo 1751.

${ }^{13}$ AHMCC., Proyecto Reforma en el jardín del Museo Provincial, Exp. 130, 1955.

${ }^{14} \mathrm{M}^{\mathrm{a}}$ J. Teixidó Domínguez, Conservación, intervenciones y práctica restauradora en el centro histórico de Cáceres (1850-1975), Tesis doctoral, Universidad de Extremadura, 2014, vol. I. p. 366. [consulta: 10/04/2018]. http:// dehesa.unex.es/handle/10662/85/brow se?value $=$ Teixid $\%$ C $3 \%$ B3+Dom $\%$ C $3 \%$ ADnguez $\% 2 C+$ Mar\%C3\%ADa+Jes\% C3\%BAs\&type=author.

${ }^{15} \mathrm{M}^{\mathrm{a}} \mathrm{J}$. Teixidó Domínguez, op. cit. vol. I. p. 366.

${ }^{16}$ AMCC., Obras y Servicios, 218, 1961. Proyecto de jardín de la casa de las Veletas.

${ }^{17}$ AHMCC. Obras y Servicios, 47, 1938. $M^{a}$ Jesús Teixidó Domínguez lo incluyó por primera vez en su tesis doctoral.

${ }^{18} \mathrm{~J}$. Clemente Simón, "Cáceres convierte su ciudad medieval en una enorme galería de arte 100 creadores de España y América participan en Foro Sur" [Consulta: 10/10/2017]. https:// elpais.com/diario/2001/04/06/cultura/986508004_850215.html.

${ }^{19} \mathrm{M}^{\mathrm{a}}$ M. Lozano Bartolozzi, "Don Xavier de Salas y Trujillo, la huella de una aquilatada sensibilidad.", en Estudios Xavier de Salas (Mercedes Águeda Villar, ed.), Universidad de Extremadura, Badajoz, 2010, pp. 17-37.

${ }^{20}$ Consuelo Correcher ha sido Profesora Titular de Historia del Jardín en la Escuela de Jardinería y Paisajismo Castillo de Batres desde 1976. Ha impartido clases de Historia del Jardín y de Restauración de Jardines Históricos en numerosas universidades y otros centros. Ha realizado innumerables proyectos e investigaciones en Jardines Históricos. Fue fundadora, Presidenta y Miembro de Honor de la Sociedad de Amigos del Real Jardín Botánico, Presidenta del Instituto de Estudios de Jardinería y Arte Paisajismo y miembro de la Junta Directiva de la Asociación Hispania Nostra.

${ }^{21}$ [Consulta: 12/12/2017]. http:// www.canalextremadura.es/tv/entretenimiento/el-lince-30\#programas-completos-tv.

${ }^{22}$ Biblioteca Fundación Xavier de Salas. Memoria del proyecto de Recreación de la Huerta del Museo Convento de la Coria, Trujillo, Cáceres. Paisajista Jesús Martín y Hernandez Cañizares, 1999. Fundación Caja Madrid Fundación Hispania Nostra.

${ }^{23}$ A. Navareño Mateos, Arquitectura residencial en las dehesas de la tierra de Cáceres, Institución Cultural "El Brocense" Excma. Diputación de Cáceres, Cáceres, 1999, pp.101-110.

${ }^{24}$ Agradecemos a don Ramón Jordán de Urríes y Martínez de Galinsoga, Vizconde de Roda que nos haya facilitado la memoria del proyecto de la cual reproducimos algunos textos entrecomillados.

${ }^{25}$ [Consulta: 12/12/2017]. http:// www.canalextremadura.es/tv/entretenimiento/el-lince-30\#programas-completos-tv. 


\section{REFERENCIAS}

Cerrillo Martín de Cáceres, Enrique. 2017. La desconstrucción de la muralla de Cáceres. Cáceres: Ayuntamiento de Cáceres.

Clemente Simón, Jeremías. 2001. "Cáceres convierte su ciudad medieval en una enorme galería de arte 100 creadores de España y América participan en Foro Sur." El País, Abril 6, 2017. Accessed: 10/10/2017. https://elpais.com/diario/2001/04/06/cultura/986508004_850215. html.

Lozano Bartolozzi, María del Mar. 1980. “Una utopía constructiva: Proyecto de un palacio en el Cáceres del siglo XVIII que no se llegó a realizar." Academia. Boletín de la Real Academia de Bellas Artes de San Fernando 50: 159-186.

Lozano Bartolozzi, María del Mar. 1984. “El Arca del Albano: Jardín de Abadía." Periferia, vol. II: 78-90.

Lozano Bartolozzi, María del Mar. 2010. “Don Xavier de Salas y Trujillo, la huella de una aquilatada sensibilidad." In Estudios Xavier de Salas, edited by Mercedes Águeda Villar, 17-37. Badajoz: Universidad de Extremadura.

Maldonado Escribano, José. 2014. "La Cuenca del río Tajo y sus casas de campo en la Alta Extremadura." In Patrimonio cultural vinculado con el agua: paisaje, urbanismo, arte, ingeniería y turismo, coords. María del Mar Lozano Bartolozzi, Vicente Méndez Hernán, 171-188. Mérida: Editora Regional de Extremadura.
Martín y Hernández Cañizares, Jesús. 1999. Memoria del proyecto de Recreación de la Huerta del Museo Convento de la Coria, Trujillo, Cáceres. Madrid: Fundación Caja Madrid-Fundación Hispania Nostra.

Martínez-Correcher y Gil, Consuelo. 2000. "Jardín Mediterráneo. El jardín tradicional mediterráneo y su papel en el ahorro del agua." In Avances en Xerojardinería, Compendio de Horticultura, 12, coord. S. Burés. Reus: Ediciones de Horticultura-Junta de Andalucía.

Navascués Palacio, Pedro. 1993. "La Abadía de Cáceres: espejo literario de un jardín. " Anuario del Departamento de Historia y Teoría del Arte 5: 71-90.

Navareño Mateos, Antonio. 1999. Arquitectura residencial en las dehesas de la tierra de Cáceres. Cáceres: Institución Cultural "El Brocense"-Diputación de Cáceres.

Ortí Belmonte, Miguel Ángel. 1932. Los Ovando y Solís de Cáceres. Badajoz.

Sayáns Castaños, Miguel Ángel, ed. 1961. Descripcion de la Ciudad y Obispado de Plasencia por Luis de Toro. Físico y Médico de Plasencia del siglo XVI. Plasencia: La Victoria.

Teixidó Domínguez, María Jesús. 2014. Conservación, intervenciones y práctica restauradora en el centro histórico de Cáceres (1850-1975). Tesis doctoral, Universidad de Extremadura. Accessed: 10/04/2018. http://dehesa.unex.es/ handle/10662/85/browse?value=Teixid $\%$ C3\% B3+Dom\%C3\%ADnguez\%2C+Mar\%C3\%A Da+Jes\%C3\%BAs\&type=author. 
